\title{
The Corner House: A Case Series on Angular Pregnancy
}

\author{
${ }^{1}$ DS Nikitha Reddy, ${ }^{2}$ Shivani Gopal, ${ }^{3}$ Chitra Andrew
}

\begin{abstract}
Introduction: Angular ectopic pregnancies implant in the intrauterine portion of the fallopian tube. Delay in diagnosis due to rarity of the condition causes high morbidity. Transvaginal two/ three-dimensional (2D/3D) ultrasound (USG) in combination with serial $\beta$-human chorionic gonadotropin (hCG) or laparoscopy confirms the diagnosis.
\end{abstract}

Materials and methods: This is a retrospective case series of all angular ectopic pregnancies seen in a 40-month period (Jan 2014-April 2017) in the Obstetrics and Gynecology Department of a tertiary referral center. Of a total 245 ectopic pregnancies, 13 cases were angular pregnancy. Data pertaining to diagnosis, USG findings, treatment, and outcomes were analyzed.

Results: Among 13 angular pregnancies, one underwent immediate surgery for rupture. All the other 12 were diagnosed at initial scan. The 2D USG followed by 3D USG was used for confirmation of diagnosis in all cases. Additional magnetic resonance imaging (MRI) was required to confirm diagnosis in 2 of the 13 patients. Methotrexate was successful in 6 of 12 cases. Four underwent single-dose regime (mean $\beta$-hCG = 1,688 $\mathrm{mlU} / \mathrm{mL}$; range: $1,105-2,401 \mathrm{mlU} / \mathrm{mL}$ ) and two required multiple doses ( $\beta$-hCG: 87,590 and $36,590 \mathrm{mlU} / \mathrm{mL}$ ). Surgical management included suction and evacuation under USG guidance in three, laparoscopic cornuostomy in two, and one laparoscopic bilateral cornuostomy with unilateral salpingostomy.

Conclusion: The 3D USG aids in the diagnosis of suspected angular pregnancy. Early recognition reduces morbidity, enabling fertility preservation. Medical and skilled surgical therapies are required for optimal outcome.

Keywords: Angular pregnancy, Cornuostomy, Methotrexate, Three-dimensional ultrasound.

How to cite this article: Reddy DSN, Gopal S, Andrew C. The Corner House: A Case Series on Angular Pregnancy. J South Asian Feder Obst Gynae 2018;10(1):40-44.

Source of support: Nil

Conflict of interest: None

Date of received: 15 January 2018

Date of acceptance: 25 February 2018

Date of publication: May 2018

\footnotetext{
${ }^{1}$ Postgraduate Student, ${ }^{2}$ Senior Resident, ${ }^{3}$ Professor

${ }^{1-3}$ Department of Obstetrics and Gynecology, Sri Ramachandra Medical College, Chennai, Tamil Nadu, India

Corresponding Author: Chitra Andrew, Professor, Department of Obstetrics and Gynecology, Sri Ramachandra Medical College, Chennai, Tamil Nadu, India, Phone: 04445928500 e-mail: chitraandrew@gmail.com
}

\section{INTRODUCTION}

Angular pregnancy has been defined as "implantation of the embryo just medial to the uterotubal junction, in the lateral angle of the uterine cavity" and medial to the round ligament. ${ }^{1,2}$ Angular pregnancy accounts for 2 to $4 \%$ of all tubal pregnancies. ${ }^{3}$ Due to abundant blood supply from the uterine, ovarian vessels, and surrounding myometrial tissue, which allows progress of the pregnancy into the second trimester, rupture occurs later in gestation compared with tubal ectopic pregnancies. The resultant catastrophic hemorrhage increases mortality rate to about $2 \%{ }^{4-9}$

Angular pregnancy has sometimes been used interchangeably with cornual and interstitial pregnancy. Cornual pregnancy refers to pregnancy that has occurred in one horn of a bicornuate uterus or septate uterus or in a rudimentary horn of a unicornuate uterus. The interstitial ectopic is that pregnancy that occurs in the interstitial part of the tube (Flow Chart 1). All of the three rare types of ectopic pregnancy share common criteria of late diagnosis and higher incidences of rupture of ectopic, thus requiring surgical intervention.

Newer modalities, such as 3D USG can give highly accurate information regarding the exact location of gestational sac and aid in differentiating between angular, interstitial, and cornual pregnancy. ${ }^{10-12}$ Magnetic resonance imaging can be used in cases where imaging with USG has been inconclusive. The main advantage of using MRI is visualization of the whole uterus to identify the exact site of implantation. ${ }^{10-12}$

Due to sequelae of these pregnancies, such as rupture of uterine wall with massive hemorrhage, placenta accreta, intrauterine growth restriction, postpartum placental retention, and postpartum endometritis, termination can

Flow Chart 1: Follow-p of the case series

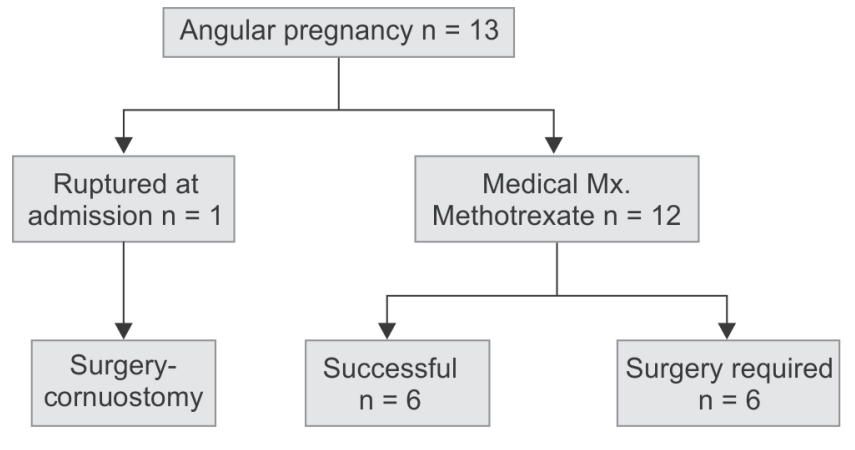


The Corner House: A Case Series on Angular Pregnancy

Table 1: Differences between cornual, angular, and interstitial pregnancy

\begin{tabular}{lll}
\hline $\begin{array}{l}\text { Cornual } \\
\text { pregnancy }\end{array}$ & Angular pregnancy & Interstitial pregnancy \\
\hline $\begin{array}{l}\text { IUGS in } \\
\text { bicornuate/ } \\
\text { septate } \\
\text { uterus }\end{array}$ & $\begin{array}{l}\text { - Located in superola- } \\
\text { eteral aspect of } \\
\text { endometrial cavity }\end{array}$ & $\begin{array}{l}\text { - Located in interstitial } \\
\text { segment of Fallopian } \\
\text { Medial to uterotubal } \\
\text { junction }\end{array}$ \\
& $\begin{array}{l}\text { GS surrounded by } \\
\text { endometrium with } \\
\text { complete adjacent } \\
\text { thick myometrial layer }\end{array}$ & $\begin{array}{l}\text { GS separate from most } \\
\text { lateral edge of uterine } \\
\text { cavity. Incomplete } \\
\text { myometrial layer } \\
\text { around the sac }\end{array}$ \\
& Medial to round ligament & $\begin{array}{l}\text { Lateral to round } \\
\text { ligament }\end{array}$ \\
\hline
\end{tabular}

GS: Gestational sac; IUGS: Intrauterine gestational sac

be opted as an approach to preserve future fertility (Table 1). ${ }^{13-16}$ There are several options to treat angular pregnancy and these vary depending on the time of diagnosis, risk factors, choice of patient, and desire for future fertility.

\section{MATERIALS AND METHODS}

This is a retrospective case series of all angular ectopic pregnancies seen in a 40-month period (Jan 2014-April 2017) in the Obstetrics and Gynecology Department of a tertiary referral center. All scans were performed using Voluson E8 (GE, Austria) with addition of 3D imaging when necessary. All images were reviewed, and diagnosis was confirmed by the same senior operator, decreasing interobserver bias. Criteria for USG diagnosis included: (a) Empty uterine cavity, (b) gestational sac seen separately less than $1 \mathrm{~cm}$ from the most lateral edge the uterine cavity, and (c) thin myometrial layer surrounding the gestational sac. Data pertaining to diagnosis, USG

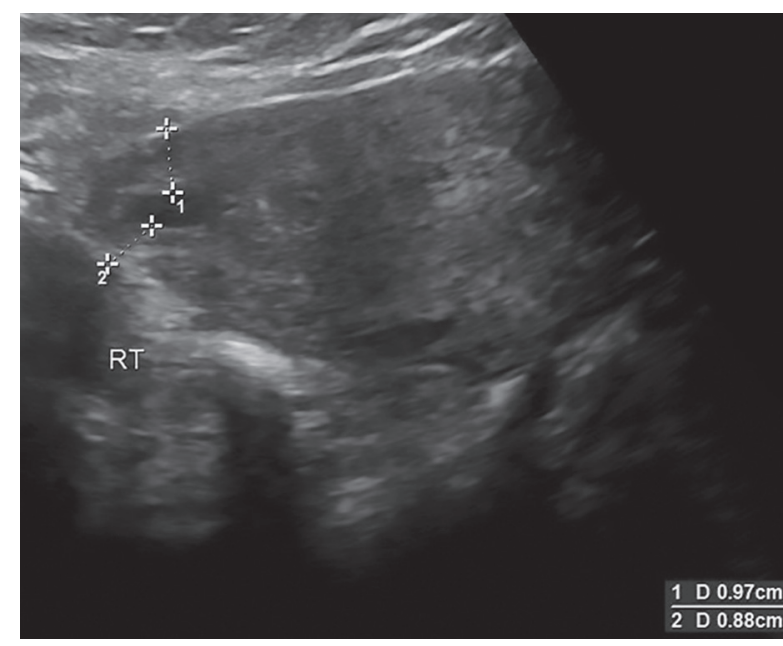

Fig. 1: The 2D view of right angular pregnancy
Table 2: Outcome of angular pregnancy ${ }^{12-16}$

\begin{tabular}{lll}
\hline Outcome & Percentage & Ratio \\
\hline Sponataneous abortion & 35 & $1 / 2$ \\
Uterine rupture in 2nd trimester & $20-35$ & $1 / 3$ \\
$\begin{array}{l}\text { Maternal mortality rate (two times } \\
\text { higher than tubal ectopic) }\end{array}$ & 0.14 & $1 / 1,000$ \\
\hline
\end{tabular}

findings, and treatment were retrieved from medical records and outcomes were analyzed.

\section{RESULTS}

Among a total of 245 ectopic pregnancies, 13 cases were diagnosed as angular pregnancy (Table 2). Transabdominal 2D USG was followed by transvaginal 2D (Fig. 1) and 3D USG (Figs 2 and 3) for confirmation of diagnosis in all cases. Additional MRI was required to confirm the diagnosis in 2 of 13 patients. The mean gestational age at diagnosis was 8 weeks +4 days $(7+1$ to $10+1)$. The mean maternal age at diagnosis was 29.4 years. Out of the 13 women, 8 were nulliparous and five patients were multigravidae. One patient underwent emergency laparotomy (cornuostomy) as she was hemodynamically unstable at time of diagnosis (Fig. 4).

The other 12 patients were informed regarding the diagnosis and possible outcomes, and they opted for termination of pregnancy (Medical Termination of Pregnancy Act: 1971). These patients $(n=12)$ were initially treated with systemic administration of methotrexate at a dose of $1 \mathrm{mg} / \mathrm{kg}$. Some were treated with single-dose and others with multiple-dose regimes depending on clinical findings and clinician's preference. The protocol was explained to all women regarding the need for close monitoring and potential complications. Medical management with methotrexate was successful in 6 of the 12 cases.

Four underwent single-dose regime with a mean $\beta-\mathrm{hCG}=1,688 \mathrm{mIU} / \mathrm{mL}(1,105-2,401 \mathrm{mIU} / \mathrm{mL})$ and

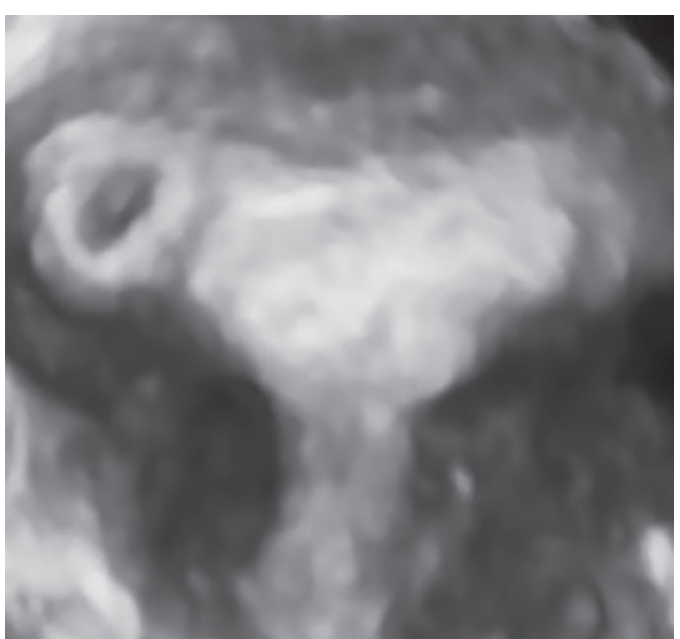

Fig 2: The 3D render view of right angular pregnancy 


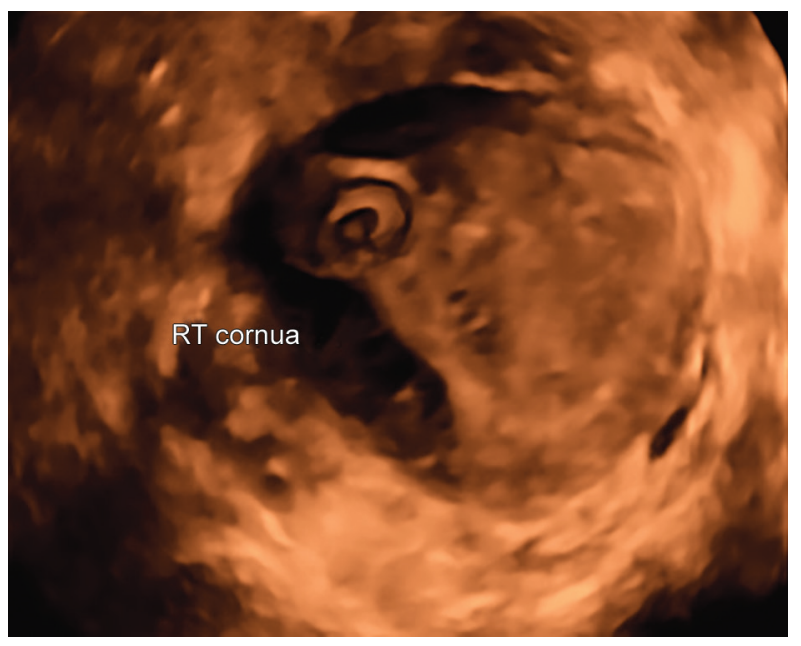

Fig. 3: The 3D omni view of right angular pregnancy

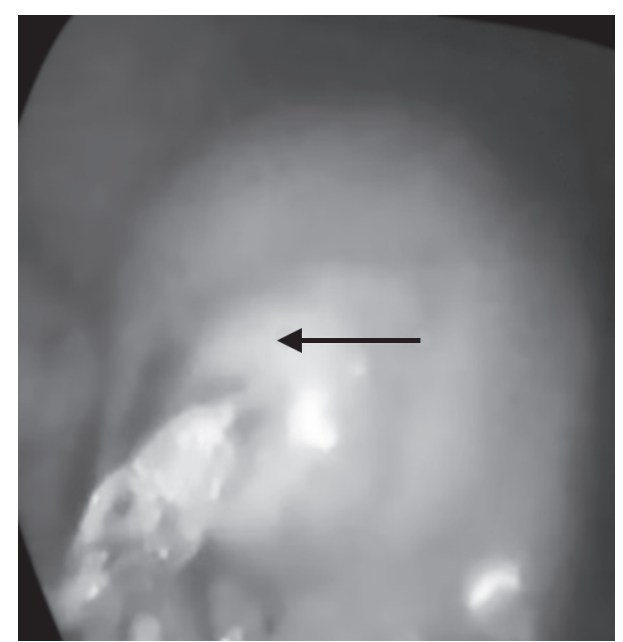

Fig. 4: Right angular pregnancy with escape of amniotic fluid two required multiple doses ( $\beta$-hCG: 87,590 and $36,590 \mathrm{mIU} / \mathrm{mL}$ ).

Multidose regime was administered on D1, D3, and D7 with a combination of folinic acid administered intramuscularly at a dose of $0.1 \mathrm{mg} / \mathrm{kg}$ on D2, D4, and D6 as per standard protocols. Follow-up of $\beta$-hCG was done weekly in all women until negative results were obtained, and one among these women is currently having an uneventful intrauterine ongoing pregnancy.

Six women required surgical intervention in view of failed medical management. This included suction and evacuation (S\&E) under USG guidance in three and laparoscopic cornuostomy in three. Among the three patients who underwent laparoscopic cornuostomy, one was a rare case with bilateral angular pregnancies diagnosed by 2D and 3D USG and confirmed by MRI. The pregnancy was precious as the mother was a primigravida at 39 years, who conceived spontaneously after 16 years of marriage. She was unwilling for termination and, hence, managed expectantly for 2 weeks. Following that, as the MRI showed thinning of the myometrium, termination of pregnancy was opted with multipledose regime. However, there was no response, and fetal cardiac activity in both angular sacs was noted on follow-up scans; surgery was opted for. During surgery, bilateral cornuostomy was first performed. Following this, hemoperitoneum was noted with a distended left fallopian tube and, hence, unilateral salpingostomy was also performed. Histopathology confirmed the presence of villi indicating that this was a triplet ectopic pregnancy with bilateral angular and one tubal ectopic pregnancy. This is unique as this was a natural conception. There were no intraoperative complications. Postoperative period was uneventful in all cases, and patients were followed up with serial $\beta$-hCG values, until the values were negative.

\section{Follow-Up of the Patients}

The patient who underwent bilateral cornuostomy with unilateral salpingostomy had a recurrent tubal ectopic pregnancy, which was managed medically.

Among the women, who underwent medical management, one woman had a first trimester embryonic demise, which was managed medically and another woman is having an ongoing uneventful pregnancy (currently 24 weeks of gestation) on regular antenatal visits.

\section{DISCUSSION}

Angular pregnancy has a variable presentation. Most cases are asymptomatic; some cases present with abdominal pain and vaginal bleeding. All of the three rare types of ectopic pregnancy share common criteria of late diagnosis and higher incidence of rupture of ectopic, requiring surgical intervention.

In our case series, the mean gestational age at diagnosis was $8 w+1 D$. Diagnosis at an earlier gestation helped in minimally invasive conservative surgery preceded by medical therapy. Medical therapy promoted detachment of trophoblastic tissue, making resection of gestational sac less technically difficult. This is of fundamental importance as presence of sac at the uterine angle area can cause retention of adherent chorionic tissue.

In our study, 6 patients were successfully treated with systemic administration of methotrexate. Patients who underwent medical management had minimal or no symptoms, and were hemodynamically stable with a gestational sac $<3.5 \mathrm{~cm}$ and absent fetal cardiac activity. Mean $\beta$-hCG noted in patients who underwent single-dose regime was 1,688 mIU/mL (1,105-2,401 mIU/mL).

The two patients who were successfully treated with multiple doses in view of high $\beta$-hCG values ( $\beta$-hCG: 87,590 and $36,590 \mathrm{mIU} / \mathrm{mL}$ ) were managed contrary to the guidelines of the Royal College of Obstetricians 
and Gynaecologists. These guidelines advocate medical management for patients with $\beta$-hCG less than 3,000 $\mathrm{IU} / \mathrm{L}$. We chose conservative management as these two patients were nulliparous and hemodynamically stable. Considering the very high $\beta$-hCG values, these patients were closely monitored at the hospital.

Medical management in these patients helped to preserve their reproductive function, preventing uterine scar, and complications related to anesthesia. Other case reports also discuss use of medical management in high levels of $\beta$-hCG. Tanaka et $a{ }^{17}$ had reported the first case of angular pregnancy successfully treated with multiple doses of methotrexate followed by laparoscopic cornuostomy. Starting $\beta$-hCG noted was 43,139 IU/L.

Literature states various modalities, such as injection of potassium chloride, prostaglandin, methotrexate at ectopic site under USG guidance using local hysteroscopy or under direct vision by laparoscopy. ${ }^{18-20}$ Direct administration has limitations, such as requirement of technical expertise, operator experience, and rupture during the procedure. Systemic administration offers advantages over local injection of ectopic gestation and the women were advised not to conceive within 3 months of completion of treatment. ${ }^{21}$

In cases of failed medical management, we opted for a laparoscopic approach and performed cornuostomy. Mean $\beta$-hCG noted in our patients, who required surgical intervention following medical management, was 26,691 IU/L. Laparoscopic approach is preferred over laparotomy for unruptured cases provided a skilled laparoscopic surgeon is available. Laparoscopic approach is associated with lesser intra-operative bleeding, lesser postoperative pain, shorter hospital stay, and lesser postoperative adhesions. ${ }^{4,22-24}$

Various hemostatic techniques have been attempted to arrest bleeding described by Moon et al. ${ }^{25}$ These included intracorporeal and extracorporeal suturing, a harmonic scalpel, endoloop or encircling suture prior to evacuation of conception, electrosurgery in addition to dilated vasopressin injection.

In our study, transcervical approach under USG guidance had been opted for the three cases with failed medical management. The use of ultrasonic guidance is recommended due to the high risk of perforation. ${ }^{26} \mathrm{It}$ aims at disturbing the pregnancy and removing some of the products safely. ${ }^{26}$ Therefore, follow-up is essential to ensure complete resolution of the pregnancy.

Meyer has reported a case of angular pregnancy managed by operating hysteroscope. He stated that the method has advantages of restoring anatomy .The first case was published by Sanz and Verosko, ${ }^{20}$ where a case of failed medical management with multiple dose of methotrexate was treated with USG-guided removal of products of conception using polyp forceps following hysteroscopy. Zhang et $\mathrm{al}^{27}$ has reported successful management of cornual pregnancies under laparoscopically guided transcervical suction curettage without using operative hysteroscopy. Flexible suction cannula helped in aspiration of products of conception, and laparoscopic vision helped in prevention of complications, such as perforation. Bhaskar et $\mathrm{al}^{28}$ had reported a case where they used a combination of three modalities, such as hysteroscopy, laparoscopy-guided injection of vasopressin to minimize bleeding, and flexible cannula for S\&E for removal of products of conception. Selective uterine artery embolization has also been advocated as a mode of treatment in few cases.

\section{Expectant Management}

Angular ectopics are associated with higher incidence of rupture that occurs as late as 10 to 16 weeks. ${ }^{29}$ Therefore, expectant management has no place in a case confirmed as angular ectopic.

\section{Effect on Future Fertility}

These cases are associated with higher risk of recurrent ectopic compared with other types of ectopic pregnancies. There is an increased incidence of uterine rupture at the surgical site in future pregnancies in the 2nd and 3rd trimesters in cases where the prior sac excision was done, which could lead to defective myometrium and/ or the uterine cavity was opened..$^{30}$

\section{CONCLUSION}

The 3D USG aids in diagnosis of suspected angular pregnancy. Early recognition reduces morbidity, enabling fertility preservation. Medical and skilled surgical therapies are required for an optimal outcome.

\section{REFERENCES}

1. Jansen RP, Elliott PM. Angular intrauterine pregnancy. Obstet Gynecol 1981 Aug;58(2):167-175.

2. HA K. Operative gynecology. Vol II. New York: Appleton; 1898. pp. 448-449.

3. Lau S, Tulandi T. Conservative medical and surgical management of interstitial ectopic pregnancy. Fertil Steril 1999 Aug;72(2):207-215.

4. Grobman WA, Milad MP. Conservative laparoscopic management of a large cornual ectopic pregnancy. Hum Reprod 1998;13(7):2002-2004.

5. Bangsgaard N, Lund CO, Ottesen B, Nilas L. Improved fertility following conservative surgical treatment of ectopic pregnancy. Br J Obstet Gynaecol 2003 Aug;110(8):765-770.

6. Tulandi T, Saleh A. Surgical management of ectopic pregnancy. Clin Obstet Gynecol 1999 Mar;42(1):31-38.

7. Bond AL, Grifo JA, Chervenak PA, Kramers EE, Harris MA. Term interstitial pregnancy with uterine torsion: sonographic, 
pathologic and clinical findings. Obstet Gynecol 1989;73(5 Pt2): 857-859.

8. Maliha WE, Gonela P, Degnan EJ. Ruptured interstitial pregnancy presenting as an intrauterine pregnancy by ultrasound. Ann Emerg Med 1991 Aug;20(8):910-912.

9. Coady DI, Synder JR, Golstein SR, Subramanyam BR. Ultrasound diagnosis of interstitial pregnancy. NY State J Med 1985;85:655-656.

10. Elhalwagy H, Sinha P. Role of 3D ultrasound in the diagnosis of rare case of angular pregnancy. Int J Gynecol Obstet 2009;11(2).

11. Jafri SZ, Loginsky SJ, Bouffard JA, Selis JE. Sonographic detection of interstitial pregnancy. J Clin Ultrasound 1987 May;15(4):253-257.

12. Filhastre M, Dechaud H, Lesnik A, Taourel P. Interstitial pregnancy: role of MRI. Eur Radiol 2005 Jan;15(1):93-95.

13. Jansen RPS, Elliot PM. Angular intrauterine pregnancy. Obstet Gynecol 1981;58:167-175.

14. Kwon JY, Hwang SJ, Shin JE, Yoon WS, Shin JC. Two cases of angular pregnancy complicated by preterm labor and placental abruption at mid-pregnancy. J Obstet Gynaecol Res 2011 Jul;37(7):958-962.

15. Triolo O, Mancuso A, De Vivo A, Falcone S. Term angular pregnancy with placenta accreta. A case report. Clin Exp Obstet Gynecol 2004;31(2):147-148.

16. Deckers EA, Stamm CA, Naake VL, Dunn TS, McFee JG. Hysterotomy for retained placenta in a term angular pregnancy. A case report. J Reprod Med 2000 Feb;45(2):153-155.

17. Tanaka T, Hayashi H, Kutsuzawa T, Fujimoto S, Ichinoe K. Treatment of interstitial ectopic pregnancy with methotrexate: report of a successful case. Fertil Steril 1982 Jun;37(6):851-852.

18. Timor-Tritsch IE, Monteagudo A, Matera C, Viet CR. Sonographic evolution of cornual pregnancies treated without surgery. Obstet Gynecol 1992 Jun;79(6):1044-1049.

19. Goldberg M, Bider D, Oelsner G, Admon D, Maschiach S. Treatment of interstitial pregnancy with methotrexate via hysteroscopy. Fertil Steril 1992 Dec;58(6):1234-1236.
20. Sanz LE, Verosko J. Hysteroscopic management of cornual ectopic pregnancy. Inter J Obst Gynecol 2002 May;99(5 Pt 2): 941-944.

21. Royal College of Obstetricians and Gynaecologists. The management of tubal pregnancy. Green Top Guideline No. $21 ; 2004$.

22. Vermesh M, Silva PD, Rosen GF, Stein AL, Fossum GT, Sauer MV. Management of unruptured ectopic gestation by linear salpingostomy: a prospective, randomized clinical trial of laparoscopy versus laparotomy. Obstet Gynecol 1989 Mar;73 (3 Pt 1):400-404.

23. Lundorff $\mathrm{P}$, Thorburn J, Hahlin M, Keallfelt B, Lindblom B. Laparoscopic surgery in ectopic pregnancy. A randomized trial versus laparotomy. Acta Obstet Gynecol Scand 1991;70 (4-5):343-348.

24. Gray DT, Thorburn J, Lundorff P, Strandell A, Lindblom B. A cost-effectiveness study of a randomized trial of laparoscopy versus laparotomy for ectopic pregnancy. Lancet 1995 May;345(8958):1139-1143.

25. Moon HS, Choi JY, Park YH, Kim SG. New simple endoscopic operations for interstitial pregnancies. Am J Obstet Gynecol 2000 Jan;182(1 Pt 1):114-121.

26. Morgan M, Aziz M, Mikhail M, Henein M, Atalla R. Ultrasound guided treatment of cornual ectopic pregnancy. Eur J Obstet Gynecol Reprod Biol 2009 Apr;143(2):126-129.

27. Zhang X, Landi S, Trivella A, Fiaccavento A, Barbieri F. Cornual pregnancy successfully treated bysuction curettage and operative hysteroscopy. Int J Obstet Gynecol 2003 Dec;110(12):1132-1134.

28. Bhaskar P, Olayinka A, Kevin H. Hysteroscopic management of cornual ectopic pregnancy. Int J Obstet Gynecol 2003 Sep;110:879-880.

29. Abraham D, Silkowski C. Emergency medicine sonography. 1st ed.; 2010. pp. 264-274.

30. Weissman A, Fishman A. Uterine rupture following conservative surgery for interstitial pregnancy. Eur J Obstet Gynecol Reprod Biol 1992 May;44(3):237-239. 